
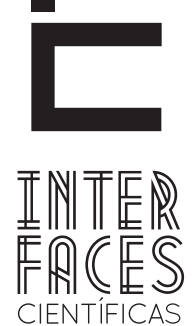

DIREITO

\title{
CONECTIVOS EM PETICÕ̃ES INICIAIS: ALGUNS APONTAMENTOS PARA ANÁLISE
}

Ludmila Brito ${ }^{1}$

Nilsandra Martins de Castro ${ }^{2}$
Bruno Gomes Pereira ${ }^{3}$

\section{RESUMO}

O presente artigo tem como objetivo analisar como ocorre o uso dos operadores argumentativos da Língua Portuguesa, também chamados de conectivos, no gênero discursivo Petição Inicial. Estamos inseridos no campo de estudos da Linguística Textual (LT), pois entendemos que o texto deve ser considerado como célula central para o desenvolvimento das análises linguísticas aqui apresentadas. A pesquisa é do tipo documental, tendo em vista que analisamos Petições Iniciais devidamente produzidas por acadêmicos do curso de direito da Faculdade Católica Dom Orione (FACDO), em Araguaína. A abordagem é qualitativa, pois consideramos a produção dos dados como algo diretamente ideológico e dedutivo. Lembramos que é a primeira vez que o corpus da pesquisa é submetido ao tratamento científico. A análise revela que o uso dos conectivos sem muita articulação gramatical com os demais elementos da cadeia sintática, o que revela uma provável dificuldade de manipular tais elementos linguísticos.

\section{PALAVRAS-CHAVE}

Petições Iniciais. Operadores Argumentativos. Gênero Discursivo. 


\section{ABSTRACT}

This article aims to analyze how is the use of argumentative operators of the Portuguese language, also called connective, the discursive genre Initial Application. We operate in the field of study of linguistics Textual (LT), because we believe that the text should be considered as central cell for the development of linguistic analyzes presented here. The research is the documentary sort, given that we analyze Initial Submissions duly produced by students of the law school of the Catholic Faculty Don Orione (FACDO) in Araguaína. The approach is qualitative, because we consider the production of data as something directly ideological

\section{RESUMEN}

Este artículo pretende analizar cómo es el uso de los operadores argumentativos de la lengua portuguesa, también llamados de conectores, en el género discursivo Petición Inicial. Operamos en el campo de estudio de la Lingüística Textual (LT), ya que entendemos que el texto debe ser considerado como la célula central para el desarrollo de los análisis lingüísticos que aquí se presentan. La investigación es del tipo documental, con el fin de analizar las Peticiones Iniciales debidamente producidas por estudiantes del curso de Derecho de la Facultad Católica Dom Orione (FACDO), en Araguaína. El enfoque es cualitativo, porque creemos en la elaboración de la información como algo and deductive. We remember that it is the first time the corpus of the research is subjected to scientific treatment. The analysis shows that the use of connective without much grammatical conjunction with the other elements of syntactic chain, which reveals a probable difficulty of handling such linguistic elements.

\section{KEYWORDS}

Initial Petitions. Argumentative Operators. Discourse Genre. directamente ideológico y deductivo. Se observa que es la primera vez que el corpus de la investigación se somete a tratamiento científico. El análisis muestra el uso de los conectores sin mucha articulación gramatical con los otros elementos de la cadena sintáctica, lo que revela una dificultad probable de manejar estos tipos de elementos lingüísticos.

\section{PALABRAS CLAVE}

Peticiones iniciales. Operadores argumentativos. Género discursivo. 


\section{INTRODUÇ̄̃O}

Este trabalho tem como foco pesquisar como ocorre o uso dos conectivos em petições iniciais produzidas por acadêmicos da Faculdade Católica Dom Orione (FACDO), trazendo a reflexão crítica a respeito dos efeitos de sentidos dos conectivos no gênero em questão. Além disso, buscamos compreender possíveis fatores contextuais que provavelmente contribuíram para o uso e significação dos conectivos no gênero analisado.

A abordagem do tema surgiu pela necessidade que há dos acadêmicos do curso de direito entenderem a relevância do estudo dos conectivos na graduação, uma vez que a petição está basicamente em tudo que se possa imaginar na formação jurídica. Em todas as disciplinas ela está aplicada, seja direta ou indiretamente, pois mesmo que a faculdade proporcione muita teoria, dela emana a prática, que é feita por meio de produção de petições.

Trazemos à apreciação dos acadêmicos da FACDO a importância semântica dos conectivos para a compreensão de um pedido, estabelecendo a relação de nitidez com o apreciador, de maneira que seu uso indevido pode emanar dúvidas que, até mesmo na hora de formular a sentença, o juiz conceda a improcedência da ação. Isso pode ocasionar prejuízo a alguma das partes por concluir que na petição inicial há contradições, alternâncias entre outros efeitos de sentido que o uso dos conectivos provoca.

A progressão acerca do conhecimento dos elementos da petição se atribui com observações de fragmentos de petições iniciais encontradas no Núcleo de Pratica Jurídica da FACDO. Nesse gênero textual há o uso exacerbado de conectivos que, por inabilidade do acadêmico, carregam o desalinho de ideias das sequências discursivas analisadas.

Ao fazer essas observações, percebe-se que a não eficiência do uso dos conectivos está ligada a não importância que se dá em descobrir a função das palavras, que afeta intimamente a compreensão da petição.

Além da Introdução, das Considerações Finais e das Referências, o artigo que se segue é constituído pelas seguintes partes: Relação entre texto e gênero discursivo; A estrutura da Petição Inicial e Construindo significados semântico-discursivos.

\section{RELAÇ̃̃O ENTRE TEXTO E GÊNERO DISCURSIVO}

Ao observar um determinado texto, percebemos que é dada ao escritor a faculdade de explanar ideias, intenções e motivos, dentro da finalidade proposta da escrita. Com isso, acabam revelando-se no texto impressões e marcas estilísticas do autor.

Sabemos que o texto é "lugar de interação de sujeitos sociais, os quais, dialogicamente, nele se constituem e são constituídos; e que, por meio de ações linguísticas e sociocomunicativas, constroem objetos-de-discurso" (KOCH; ELIAS, 2006, p. 7). Em outras palavras, o texto constitui sentidos evidenciados por meio de escolhas gramaticais e organizacionais.

Quanto às escolhas, é inerente a noção de que todo texto proporciona uma gama de relações implícitas que só podem ser interpretadas por meio do contexto sociocognitivo vivenciado pelos atores sociais. Por isso, Marcuschi (2002) afirma que só nos comunicamos por meio de gêneros. Estes, por sua vez, são definidos como tipos relativamente estáveis de enunciados elaborados pelas mais diversas esferas da atividade humana (BAKHTIN, 1997).

Podemos dizer que gêneros são eventos linguísticos inerentes a qualquer sociedade. Temos a necessidade de nominar os objetos e eventos a nossa volta. Por isso, chamamos de gêneros todos os eventos comunicativos fundamentais para a socialização e que dão legitimidade aos discursos, falados ou escritos.

Nessa esfera, podemos citar a Petição Inicial como um gênero discursivo representativo da área do direito, sendo um instrumento primário para se iniciar qualquer processo. Como qualquer outro texto, requer uma sistematização e organização de ideias, sendo que todas elas partem de modelos, os quais, sequencialmente, contribuem para a escrita de outros textos jurídicos. 
Os gêneros garantem a ordenação e estabilidade dos eventos comunicativos, seja a argumentação oral em um julgamento, seja a produção de um artigo científico. Bakhtin (1992) afirma que os gêneros discursivos são frutos das sociedades e de sua organização histórico-social e que são sempre variados. A relação entre a realidade e os sujeitos que dela compõem é que fazem os gêneros discursivos responderem as necessidades dos agentes.

Um dos fatores mais relevantes para a escolha do gênero discursivo ora referido é a percepção de coesão inerente à interpretação feita por julgadores, no âmbito do direito. Usá-la de maneira correta é uma tarefa nada fácil, pois se não nos atentarmos aos elementos intrínsecos de cada gênero, seus pontos que refletem uma interpretação clara e concisa, dificilmente poderá obter êxito nos pedidos da petição. Dessa forma, diz Costa (2003, p. 3) que "o texto, então, passou a ser considerado como uma unidade significativa".

Essa unidade significativa pressupõe a noção de textualidade, que seriam os elementos intrínsecos que fazem com que um texto seja um texto e não um amontoado de palavras. Diz Beaugrande e Dressler (1981, APUD COSTA, 2003, p. 3) que os fatores de textualidade são:

[...] coerência, coesão - centrados no texto - e, intencionalidade, aceitabilidade, situacionabilidade, informatividade e intertextualidade - centrados no usuário. Esses critérios definem e criam à comunicação verbal e, a ausência deles pode acarretar o rompimento da comunicação.

Porquanto, para que possamos construir textos significativos, devemos observar os critérios de textualidade informados acima. Com tudo o que viemos afirmando, podemos dizer que todo texto tem suas peculiaridades, tem seus pontos específicos que devem ser atendidos para que, em um todo, possa ter a organização de ideias e significados que garantam a finalidade da informação. No caso da Petição Inicial, esta requer a formalidade constitutiva do seu formato, sob pena de os órgãos julgadores a indeferirem pela não observância dos elementos obrigatórios próprio desse gênero. Silva (1999, p. 6) nos ensina que:

[...] Quaisquer que sejam a extensão, o conteúdo semântico, os recursos linguísticos e a sua composição estrutural, o discurso, materializado na forma de texto, apresenta características que lhe são geralmente comuns, moldadas pelas regras do funcionamento do (s) gênero(s), essas, por sua vez, articuladas no interior das interações das esferas das relações sociais.

0 acadêmico de direito deve ser um exímio observador da linguagem da coesão e do raciocínio lógico, que, no ordenamento jurídico, é amplamente necessário.

\section{ESTRUTURA DA PETIÇ̃̃O INICIAL}

De acordo com Sabbag (2009), a petição inicial deve ser analisada tendo por base o silogismo que considera duas premissas, uma maior e outra menor, para depois se chegar a uma conclusão.

A premissa menor é a exposição fática, e a premissa maior é a fundamentação jurídica, por haver previsão legal diante daquele determinado fato. Em outras palavras, deve haver a articulação entre os fatos apresentados, a legislação aplicável e os devidos pedidos. Tudo que é articulado nos fatos e na fundamentação deve ser sistematizada, pois na conclusão deve aparecer tudo o que foi apresentado inicialmente.

Considerando a seção anterior, a petição é um gênero discursivo. Desse modo, traz consigo elementos específicos que fazem parte de sua constituição. Assim, a petição inicial terá como alvo um leitor contestador, que é a outra parte, no caso o réu, e terá também o leitor julgador que, a partir dele, terá uma decisão referente à matéria explanada na petição.

A petição segue técnicas, estética e estruturas próprias do gênero. Dentro da petição, na explanação fática e na fundamentação jurídica, há presença evidente dos conectivos, uma vez que depende da sequência argumentativa por parte do acadêmico de direito. Este, com toda sua capacidade persuasiva e com o uso dos conectivos adequados, poderá repassar coerentemente ao leitor a sua versão dos fatos. 
Na explanação fática fica livre ao acadêmico do direito, com sua escrita e argumentação textual, demonstrar seu domínio tanto em relação à gramática, quanto, também, ao sentido de cada frase e palavra no seu momento oportuno.

Didier Jr. (2012, p. 441) diz que:

Deve, assim, o autor, em sua petição inicial, expor todo o quadro fático necessário à obtenção do efeito jurídico perseguido, bem como demonstrar como os fatos narrados autorizam a produção desse (deverá o autor demonstrar a incidência da hipótese normativa no suporte fático concreto).

Assim, grande é a importância dos conectivos nesse momento, pois seu uso adequado trará significações aos fatos, darão sequência ao discurso, considerando cada âmbito fático. 0 uso inadequado desses elementos de coesão pode dificultar o entendimento do texto.

Já na fundamentação jurídica, o acadêmico deve enfatizar o que está expresso na lei, de maneira parafraseada, as suas ligações e a sua harmonização. Além disso, espera-se que o acadêmico de direito vincule, também, o que já há escrito sobre determinado fato à linguagem técnica que o ordenamento jurídico comporta, relacionando, assim, ao caso apreciado.

0 manuseio dos conectivos nessa etapa é essencial para demonstrar a habilidade de articulação da fundamentação jurídica, se ela está compatível ou não com a explanação fática. Dado que haja um uso inadequado do conectivo, a progressão temática do texto é comprometida, levando-o a não apresentar argumentos novos para a fundamentação do tópico frasal.

Por conseguinte, temos o requerimento, que, para a conclusão da petição, deve ser articulado habilmente às outras partes do texto, de maneira a concluir o pensamento inicial. Nesse momento, os operadores argumentativos desempenham função basilar na concatenação das ideias e unidade do gênero discursivo.

Sobre os pedidos, Lenza (2013) nos ensina que deve ser emergente o pedido de maneira clara e direta, por se tratar de consequência jurídica. Por se tratar de um resultado almejado por quem está devidamente em consonância com a tipificação legal, e por ter no conflito amparo legal, deve-se dar a ele um resultado.

Com isso, no gênero discursivo analisado, os conectivos comumente conduzem o discurso para uma ideia de conclusão, prioridade e ênfase, pois encerram as proposições apresentadas na petição, findando com a argumentação textual e semântica da peça.

\section{CONSTRUINDO SIGNIFICADOS SEMÂNTICO- -DISCURSIVOS}

Ao analisar as petições do Núcleo de Prática Jurídica da FACDO, é nítido o quão é essencial o uso dos conectivos para a harmonização semântica entre as partes que constituem o gênero em questão.

Em uma das petições selecionadas para essa pesquisa, uma “Ação de Regulamentação de Guarda”, dentro da fundamentação jurídica, temos a exemplificação da produção de determinado acadêmico:
0 art. 22 do Estatuto da criança e do Adolescente preceitua que é competência dos pais a guarda dos filhos menores:

Art. 22. Aos pais adjudica o dever de sustento, guarda e educação dos filhos menores. cabendo-lhes ainda no interesse destes, a obrigação de cumprir e fazer cumprir as determinações judiciais. (Grifo nosso)

De acordo com o Parágrafo $1^{0}$ do artigo 33 do mes mo estatuto legal a guarda tem por fim regularizar a posse de fato...

Partindo do pressuposto de que os operadores argumentativos estabelecem uma relação de sentido entre os elementos formadores de sequências sintáticas, tornou-se indispensável o uso de conectivos conclusivos ou explicativos após a citação, para findar, discordar, concordar, ou até mesmo justificar o dispositivo legal citado.

Sem a aplicabilidade desses conectivos, há uma quebra na ideia das sequências gramaticais, impossibilitando a compreensão do próprio fato explanado na petição, com as normas cabíveis e preexistentes que embasam o pedido. 
Em um trecho de uma petição de "Ação de exoneração de pensão alimentícia à ex- cônjuge $c /$ pedido de antecipação de tutela", na exposição fática, o acadêmico utilizou o seguinte parágrafo:

Por fim, não dispondo mais de meios para arcar com, suas obrigações, no que diz respeito aos alimentos fixados à Requerida, as partes firmaram acordo nos autos dos processos retro mencionados e, por meio de terceira pessoa de boa fé e interessada no fim do litígio, o referido débito alimentar foi quitado integralmente, pelo valor de [...].

Neste excerto, podemos evidenciar a presença dos conectivos que, ao examinarmos seus possíveis significados, entendemos que eles foram utilizados, nesse início do texto, para dar sucessão às informações sequenciadas.

0 acadêmico, possivelmente, constatou a necessidade de usar esse elemento de conexão para concluir que, com aqueles motivos acima descritos, o requerente não havia mais condição financeira para custear suas inadimplências.

O outro conectivo sublinhado, o "e", nos sugere o significado de complemento, continuidade, para acrescentar mais uma informação de relevância, que, no destacado, é a intervenção de uma pessoa para solucionar o conflito.

Em outra petição analisada, uma "Ação de Reparação de danos morais e materiais”, na fundamentação jurídica, fizemos a seguinte observância:

“Assim, podemos nos pautar na doutrina e também no legislador pátrio, que inferem a responsalização objetiva nas relações de consumo, eis que, na maioria das vezes..."

Esse excerto foi extraído da fundamentação jurídica, onde estão presentes referências de outros textos dentro da mesma peça, na sequência de um posicionamento. Logo, deve vir a sua apreciação, no tocante ao entendimento do caso apresentado. Por meio do conectivo sublinhado, notamos que o acadêmico utilizou tal elemento coesivo para concordar com o argumento acima apresentado. Dessa forma, essa con- cordância gera efeitos de sentido típicos do gênero discursivo analisado, tais como confluência de argumentos e diálogo harmonioso entre as diversas vozes que compõem a peça.

Observando outra Petição de "Ação de Usucapião Extraordinário", apontamos os seguintes pressupostos:

O imóvel usucapiendo confronta: com a propriedade da Sra Itamar Barbosa de Sousa, residente e domiciliada à Rua das Mangueiras, n 33, Vila Norte, na

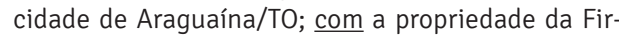
ma Emar Empreendimentos Araguaia LTDA, pessoa jurídica de direito privado, com sede à SDS - Edifício Venâncio III, sala 405, na cidade de Brasília/DF e com a propriedade do Sr. Celiomar de Souza Mendes, residente e domiciliado na Av. Cônego João Lima, n 1974, Bairro Neblina, na cidade de Araguaína.

Percebemos que, devido ao uso exacerbado do conectivo "com", notamos certo desvirtuamento do significado desse elemento coesivo, tornando a sequência gramatical cansativa, ao passo que acumula diferentes sentidos, impossibilitando a coerência do texto.

Sabendo que o emprego do conectivo "com" nos remete à ideia adição e continuidade, os dois primeiros conectivos sublinhados nos remetem à confrontação residencial. Já no terceiro, repete-se o mesmo conectivo, sendo que ali não há função de nos remeter a mais uma confrontação residencial, mas sim ao endereço que a empresa que faz confrontações é situada. Em seguida, o acadêmico não utiliza outro conectivo para voltar a fazer referência à confrontação da residência do imóvel usucapiendo, ele continua empregando o mesmo operador argumentativo.

Esse emaranhado de informações diferentes impossibilita a compreensão do texto, nos levando a entender que todos os endereços situados fazem confrontações. Nesse sentido, a repetição exacerbada do mesmo conectivo confere uma espécie de ambiguidade aos argumentos do gênero em questão, frutos de uma estrutura sintática mal elaborada. 


\section{CONSIDERACÕES FINAIS}

Analisar o uso dos elementos linguísticos em sequências textuais mais complexas é algo, no mínimo, desafiador. Para entendermos como as escolhas gramaticais refletem os sentidos das estruturas sintáticas de um texto, é necessário considerarmos fatores exofóricos que atuam diretamente na composição do gênero discursivo.

A concepção de gênero nos ajudou a repensar o papel semântico dos operadores argumentativos, bem como a necessidade que temos em conhecê-los para usá-los adequadamente. 0 uso adequado desses elementos propicia uma escrita melhor elaborada, pois a escolha consciente dos elementos gramaticais pode ajudar no manuseamento das ideias e dos argumentos que costuram o texto.

Pensamos que as Petições Iniciais que analisamos são exemplos claros de que é necessário um bom uso dos operadores argumentativos, de maneira a tornar o texto coerente, claro e objetivo.

\section{REFERÊNCIAS}

BAKHTIN, Mikhail. Estética da criação verbal. 2.ed. São Paulo: Martins Fontes, 1997.

BEAUGRANDE, Robert de; DRESSLER, Wolfgang. Introduction to text linguistics. London: Longman, 1981.

COSTA, Giselda dos Santos. Texto e coesão textual. 2003. [Online] Disponível em: $<$ http://www.academia.edu/5001299/Texto_e_coes\%C3\%A3o_textual $>$. Acesso em: 19 set. 2014.
DIDIER JR., Fredie. Curso de direito processual civil: Introdução ao direito processual civil e processo de conhecimento. 14.ed. Bahia: JusPodivm, 2012.

GONÇALVES, Marcos Vinicius Rios. Novo curso de direito processual civil. 9.ed. São Paulo: Saraiva, 2012.

KOCH, Ingedore Villaça; ELIAS, Vanda Maria. Ler e compreender: os sentidos do texto. 5.ed. São Paulo: Contexto, 2006.

LENZA, Pedro (Org.). Direito processual civil esquematizado. São Paulo: Saraiva, 2013.

MARCUSCHI, Luiz Antonio. Gêneros textuais: definição e funcionalidade. In: DIONISIO, A. P. et al. (Org.). Gêneros textuais \& ensino. Rio de Janeiro: Lucerna, 2002. p.19-36.

PEREIRA, Ézio Luiz. Da petição inicial. 6.ed. São Paulo: Edijur, 2011.

SABBAG, Eduardo de Moraes. Redação forense e elementos da gramática. 3.ed. São Paulo: Premier Máxima, 2009.

SILVA, Jane Quintiliano Guimarães. Gêneros discursivos e tipo textual. Minas Gerais: SCRIPTA, v.2, n.4 $-1^{\circ}$ sem, 1999. p.87-106. 
Recebido em: 10 de Setembro 2015

Avaliado em: 12 de Setembro de 2015 Aceito em: 30 de Setembro de 2015
1. Graduanda em Direito pela Faculdade Católica Dom Orione (FACDO), campus de Araguaína. E-mail: ludimila.brito@hotmail.com.

2. Doutoranda em Ensino de Língua e Literatura (Estudos Linguísticos) pela Universidade Federal do Tocantins (UFT), campus universitário de Araguaína. Professora da Faculdade Católica Dom Orione (FACDO), campus de Araguaína, onde ministra as disciplinas Língua Portuguesa Aplicada ao Direito, Redação Jurídica e Monografia Aplicada ao Direito. E-mail: nillsandra@gmail.com.

3. Doutorando em Ensino de Língua e Literatura (Estudos Linguísticos) pela Universidade Federal do Tocantins (UFT), campus universitário de Araguaína. Professor da UFT. E-mail: brunogomespereira_30@hotmail.com. 